\title{
Analisis Kebutuhan Pengembangan Booklet Sistem Imun Manusia sebagai Suplemen Bahan Ajar Biologi Kelas XI SMA
}

\section{Olla Krisliani Yudistira ${ }^{1}$, Syamsurizal2 ${ }^{2}$, Helendra ${ }^{3}$, Yusni Attifah ${ }^{4}$}

1,2,3,4 Universitas Negeri Padang, Padang, Indonesia

\section{A RT I CLE INFO}

Article history:

Received February 12, 2021

Revised February 27, 2021

Accepted March 20, 2021

Available online April 25, 2021

Kata Kunci:

Booklet, Suplemen Bahan Ajar, Biologi

Keywords:

Booklet, Teaching Material

Supplement, Biology

\section{A B S T R A K}

Pemilihan bahan ajar yang sesuai dengan kebutuhan peserta didik bukanlah hal yang mudah, guru harus mengetahui bagaimana karakteristik peserta didik untuk dapat menyesuaikan bahan ajar yang digunakan. Penelitian ini bertujuan untuk menganalisis kebutuhan pengembangan booklet sistem imun manusia sebagai suplemen bahan ajar biologi. Penelitian ini termasuk kedalam jenis penelitian deskriptif. Subjek penelitian ini adalah 159 peserta didik kelas XII IPA dan satu orang guru biologi. Objek penelitian ini adalah hasil analisis kebutuhan pengembangan booklet sistem imun manusia sebagai suplemen bahan ajar biologi. Metode pengumpulan data yang digunakan adalah metode non-tes dan instrumen yang digunakan berupa angket. Teknik analisis data yang digunakan adalah teknik analisis data statistik deskriptif kuantitatif. Hasil penelitian ini menunjukkan bahwa peserta didik dan guru biologi diperoleh data bahwa peserta didik membutuhkan sumber belajar tentang materi sistem imun manusia yang dapat dipahami secara mandiri sebanyak $91,2 \%$ peserta didik menginginkan sumber belajar berbentuk booklet. Simpulan penelitin ini adalah pengembangan booklet sebagai suplemen bahan ajar biologi dapat menjadi solusi dari permasalahan yang dihadapi oleh guru dan peserta didik khusunya pada materi sistem imun manusia.

\section{A B S T R A C T}

The selection of teaching materials that suit the needs of students is not an easy thing, the teacher must know how the characteristics of students are to be able to adjust the teaching materials used. This study aims to analyze the need for developing human immune system booklets as a supplement to biology teaching materials. This research is included in the type of descriptive research. The subjects of this study were 159 students of class XII science and one biology teacher. The object of this research is the analysis of the need for the development of the human immune system booklet as a supplement to biology teaching materials. The data collection method used is a non-test method and the instrument used is a questionnaire. The data analysis technique used is the descriptive quantitative statistical data analysis technique. The results of this study indicate that students and biology teachers obtained data that students need learning resources about the human immune system material that can be understood independently as many as $91.2 \%$ of students want learning resources in the form of booklets. The conclusion of this research is that the development of booklets as a supplement to biology teaching materials can be a solution to the problems faced by teachers and students, especially on the subject of the human immune system.

\section{Pendahuluan}

Pemanfaatan media yang relevan di dalam kelas dapat mengoptimalkan proses pembelajaran (Aprinawati, 2017; Khaulani et al., 2019; Ulfah \& Soenarto, 2017). Bagi guru, media pembelajaran membantu mengkonkritkan konsep atau gagasan dan membantu memotivasi peserta belajar aktif. Bagi siswa, media dapat menjadi jembatan untuk berpikir kritis dan berbuat. Dengan demikian media dapat membantu tugas guru dan siswa untuk mencapai kompetensi dasar yang telah ditetapkam. Media pembelajaran dapat dikatakan sebagai salah satu saranan yang berguna untuk meningkatkan mutu pendidikan dalam proses pembelajaran (Maharwati, 2019; Sribawana et al., 2017; Wicaksono et al., 2020). Media pembelajaran adalah segala sesuatu (bisa berupa alat, bahan, atau keadaan) yang digunakan sebagai perantara komunikasi dan dapat merangsang pikiran, perasaan, perhatian serta kemampuan atau 
keterampilan guru sehingga dapat mendorong terjadinya proses pembelajaran (Firdaus et al., 2018; Handayani et al., 2017; Kawi, 2019). Media pembelajaran digunakan sebagai alat bantu oleh guru untuk berkomunikasi dengan peserta didik dalam proses pembelajaran agar menjadi lebih efektif dan efisien (Rivaldi et al., 2018; Wicaksana, 2017; Wintarti, 2017). Pemilihan media pembelajaran harus disesuaikan dengan karakteristik peserta agar materi yang disampaikan menjadi lebih bermakna, dapat diterima, dipelajari dan dipahami peserta didik, sehingga guru dituntut kreatif dalam mengembangkan media pembelajaran (Pradilasari et al., 2019; Septiani \& Hasanah, 2019; Sulfemi \& Mayasari, 2019). Salah satu sarana yang dapat menampung kreativitas guru yaitu mengadakan variasi dalam penggunaan alat dan media pembelajaran, variasi tersebut bertujuan untuk meningkatkan perhatian peserta didik dalam proses pembelajaran (Bayu \& Wahyuni, 2019; Septiawan, 2018; Yusantika et al., 2018). Berdasarkan observasi yang telah dilakukan di SMAN 4 Padang sebanyak 56,6\% peserta didik kesulitan memahami sumber belajar yang disediakan sekolah. Sebanyak $93,1 \%$ peserta didik membutuhkan sumber belajar lain untuk menunjang pemahaman terhadap materi, hal ini sejalan dengan pendapat Dra. Neng Mulyetti selaku guru biologi di SMAN 4 Padang, guru membutuhkan sumber belajar lain pendamping bahan ajar utama yang disediakan sekolah karena banyaknya istilah-sitilah sulit yang sulit dipahami dan tidak ada penjelasan yang jelas, sehingga bahan ajar yang disediakan sekolah tidak bisa dipahami oleh peserta didik tanpa penjelasan dari guru.

Materi biologi yang dipelajari peserta didik kelas XI SMA salah satunya adalah sistem imun manusia. Berdasarkan hasil angket yang disebarkan kepada 159 peserta didik kelas XII SMAN 4 Padang sebanyak $76,1 \%$ peserta didik mengatakan sulit memahami materi sistem imun manusia, kesulitan tersebut dikarenakan banyaknya istilah-istilah yang membingungkan dan materi sistem imun yang bersifat hafalan, sehingga peserta didik membutuhkan sumber belajar penunjang untuk meningkatkan pemahaman pada materi sistem imun manusia. Salah satu media pembelajaran yang dapat digunakan sebagai sumber belajar tambahan oleh peserta didik yaitu booklet. Booklet merupakan buku kecil berisi informasi baik berupa gambar atau tulisan, dan berfungsi sebagai selebaran (Paramita et al., 2019; Rehusisma et al., 2017; Yusuf et al., 2019). Booklet dapat menjadi salah satu alternatif yang digunakan oleh guru karena menggunakan bahasa yang mudah dimengerti oleh peserta didik. Media booklet memiliki keunggulan diantaranya mudah dibawa, karena berukuran kecil dan tipis, dilengkapi penjelasan yang ringkas dan sistematis sehingga mudah dipahami, namun tetap variatif dibandingkan dengan buku pelajaran, bahasa yang digunakan juga lebih mudah dipahami dan komunikatif, serta dilengkapi dengan gambar-gambar sebagai ilustrasi sehingga mempermudah dalam memahami penjelasan (Nuzalifa et al., 2019; Ulya, 2014; Yulianti et al., 2019). Booklet diharapkan dapat menjadi media pembelajaran yang dapat meningkatkan efektivitas pembelajaran peserta didik, salah satu kegunaan booklet yaitu sebagai suplemen bahan ajar.

Suplemen bahan ajar adalah bahan ajar yang menjadi pendamping bahan ajar pokok yang telah diterbitkan oleh pemerintah, suplemen bahan ajar biasanya berisi pengembangan materi sehingga pemahaman terhadap materi tersebut lebih luas (Owon \& Adi, 2017; Putri et al., 2018; Ramadhani et al., 2016). Sumplemen bahan ajar dapat dimanfaatkan oleh guru untuk membantu pelaksanaan pembelajaran, agar dapat membuat pelaksanaan pembelajaran lebih efektif dan siswa lebih memahami materi yang disampaikan oleh guru (Muharram et al., 2010; Putri et al., 2018; Wahyuning et al., 2017). Sehingga, penting dilaksanakan pengembangan mengenai analisis kebutuhan pengembangan booklet sistem imun manusia sebagai suplemen bahan ajar biologi. Penelitian ini di dukung beberapa penelitian terdahulu yang relevan dengan penelitian ini, seperti: (1) penelitian yang dilakukan oleh (Rehusisma et al., 2017), yang mendapatkan hasil penelitian yaitu pengembangan media pembelajaran booklet dan video dapat menguatkan karakter hidup bersih dan sehat siswa; (2) penelitian yang dilakukan oleh (Nuzalifa et al., 2019), yang mendapatkan hasil penelitian yaitu pengembangan media pembelajaran booklet dapat digunakan untuk membantu penyuluhan tentang pembuatan nata de melon bagi masyarakat petani; (3) penelitian yang dilakukan oleh (Yusuf et al., 2019), yang mendapatkan hasil penelitian yaitu pengembangan bahan ajar perang lasem dalam bentuk booklet efektif digunakan untuk membantu pelaksanaan pembelajaran sejarah. Tujuan penelitian pengembangan ini adalah untuk menganalisis kebutuhan pengembangan booklet sistem imun manusia sebagai suplemen bahan ajar biologi kelas XI di SMAN 4 Padang. Hasil dari penelitian ini digunakan untuk mengembangkan sumber belajar berupa booklet pada penelitian selanjutnya.

\section{Metode}

Penelitian ini termasuk kedalam jenis penelitian pengembangan. Namun, karena keterbatasan penelitian, pelaksanaan penelitian pengembangan ini dilaksanakan hanya sampai tahap analisis kebutuhan mengenai pengembangan booklet sistem imun manusia sebagai suplemen bahan ajar biologi. Penelitian ini dilaksanakan di SMAN 4 Padang pada tanggal 26 oktober 2020. Subjek penelitian ini adalah 
159 peserta didik kelas XII IPA dan satu orang guru biologi. Objek penelitian ini adalah hasil analisis kebutuhan pengembangan booklet sistem imun manusia sebagai suplemen bahan ajar biologi kelas XI di SMAN 4 Padang. Metode pengumpulan data yang digunakan adalah metode non-tes dan instrumen yang digunakan berupa angket. Pengumpulan data dilakukan dengan menyebarkan angket kepada peserta didik dan guru biologi melalui google form. Instrumen yang digunakan dalam penelitian ini yaitu angket ketersediaan dan penggunaan sumber belajar biologi untuk guru dan peserta didik untuk mengetahui permasalahan yang dihadapi oleh guru dan peserta didik mengenai bahan ajar yang digunakan untuk materi sistem imun manusia. Teknik analisis data yang digunakan adalah teknik analisis data statistik deskriptif kuantitatif. Data yang diperoleh dianalisis untuk mengetahui kebutuhan pengembangan booklet sistem imun manusia sebagai suplemen bahan ajar biologi kelas XI di SMAN 4 Padang. Hasil dari penelitian ini digunakan untuk mengembangkan sumber belajar berupa booklet pada penelitian selanjutnya.

\section{Hasil dan Pembahasan}

Berdasarkan data hasil angket yang disebarkan kepada peserta didik terkait kesulitan yang dialami peserta didik dalam mempelajari materi sistem imun manusia dapat dilihat pada Tabel 1.

Tabel 1. Kesulitan pada Materi Sistem Imun

\begin{tabular}{clc}
\hline No & \multicolumn{1}{c}{ Kesulitan pada Materi Sistem Imun } & Jumlah (\%) \\
\hline 1 & Materi terlalu banyak & $39,6 \%$ \\
2 & Materi bersifat hafalan & $45,3 \%$ \\
3 & Materi rumit & $15,1 \%$ \\
4 & Materi abstrak dan tidak dapat diamati secara langsung & $15,1 \%$ \\
5 & Banyaknya istilah-istilah yang membingungkan & $56 \%$ \\
6 & Kurang tersedianya sumber belajar yang baik & $35,2 \%$ \\
\hline
\end{tabular}

Dari Tabel 1, dapat dilihat kesulitan pada materi sistem imun yaitu, materi terlalu banyak 39,6 \% , materi bersifat hafalan $45,3 \%$, materi rumit $15,1 \%$, materi abstrak dan tidak dapat diamati secara langsung $15,1 \%$, banyaknya istilah-istilah yang membingungkan $56 \%$, kurang tersedianya sumber belajar yang baikc35,2\%. Sedangkan data kriteria sumber belajar yang menarik dapat dilihat pada Tabel 2.

Tabel 2. Kriteria Sumber Belajar yang Menarik Bagi Peserta Didik

\begin{tabular}{clc}
\hline No & \multicolumn{1}{c}{ Kriteria sumber Belajar } & Jumlah (\%) \\
\hline 1 & Bacaan disertai gambar & $59,1 \%$ \\
2 & Berwarna pada setiap halaman & $32,1 \%$ \\
3 & Menggunakan bahasa yang mudah dipahami & $68,6 \%$ \\
4 & Materi yang disampaikan lengkap, singkat, padat, dan jelas & $84,9 \%$ \\
5 & Berukuran lebih kecil dan praktis & $19,5 \%$ \\
6 & Ada tambahan informasi luar yang berkaitan dengan materi & $29,6 \%$ \\
7 & Terdapat penjelasan untuk istilah-istilah yang sulit & $57,2 \%$ \\
\hline
\end{tabular}

Berdasarkan pada Tabel 2. dapat dilihat kriteria sumber belajar meliputi, bacaan disertai gambar $59,1 \%$, berwarna pada setiap halaman $32,1 \%$, menggunakan bahasa yang mudah dipahami $68,6 \%$, materi yang disampaikan lengkap, singkat, padat, dan jelas 84,9\%, berukuran lebih kecil dan praktis 19,5\%, ada tambahan informasi luar yang berkaitan dengan materi $29,6 \%$, terdapat penjelasan untuk istilah-istilah yang sulit 57,2\%. Berdasarkan observasi yang peneliti lakukan pada peserta didik dan guru biologi di SMAN 4 Padang tanggal 26 oktober 2020 didapatkan data bahwa sebanyak 56,6\% peserta didik sulit memahami sumber belajar yang disediakan sekolah, kesulitan utama dikarenakan banyaknya istilahistilah rumit dalam bahan ajar yang disediakan sekolah. Sumber belajar yang biasa digunakan oleh peserta didik selama ini berupa slide ppt, LKPD, buku paket, dan modul. Guru cenderung menggunakan metode ceramah dan diskusi dalam proses pembelajaran. Salah satu materi yang dipelajari oleh peserta didik kelas XI SMA yaitu materi sistem imun manusia pada KD 3.14 yaitu menganalisis peran sistem imun dan imunisasi terhadap proses fisiologi di dalam tubuh. Menurut Ibu Dra. Neng mulyetti selaku guru biologi di SMAN 4 Padang materi sistem imun merupakan materi yang rumit, tidak dapat diamati secara langsung, banyak istilah-istilah yang membingungkan dan kurang tersedianya bahan ajar yang baik, sehingga guru membutuhkan sumber belajar lain untuk meningkatkan pemahaman peserta didik khusunya pada materi 
sistem imun manusia. Saat guru menjelaskan materi sistem imun manusia peserta didik cenderung kurang memperhatikan dengan baik, bosan saat proses pembelajaran dan terlihat kurang tertarik bahkan saat guru bertanya peserta didik tidak bisa menjawab pertanyaan guru terkait materi yang dijelaskan. Berdasarkan angket yang dibagikan kepada peserta didik dan guru biologi diperoleh data bahwa peserta didik membutuhkan sumber belajar tentang materi sistem imun manusia yang dapat dipahami secara mandiri. Sebanyak 91,2\% peserta didik menginginkan sumber belajar berbentuk booklet.

Berdasarkan kriteria sumber belajar yang menarik menurut peserta didik booklet dapat menjadi solusi permasalahan yang dihadapi oleh guru dan peserta didik. Booklet belum pernah digunakan sebagai suplemen bahan ajar biologi di SMAN 4 Padang. Booklet dapat dijadikan suplemen bahan ajar atau bahan ajar tambahan pada materi sistem imun manusia karena booklet merupakan media pembelajaran yang dapat digunakan untuk menarik minat dan perhatian siswa karena bentuknya yang sederhana dan banyaknya warna serta ilustrasi yang ditampilkan, dengan ukuran yang kecil (setengah A4), tipis dan lengkap mudahkan media tersebut untuk dibawa. Booklet merupakan buku kecil berisi informasi baik berupa gambar atau tulisan, dan berfungsi sebagai selebaran (Paramita et al., 2019; Rehusisma et al., 2017; Yusuf et al., 2019). Booklet dapat menjadi salah satu alternatif yang digunakan oleh guru karena menggunakan bahasa yang mudah dimengerti oleh peserta didik. Media booklet memiliki keunggulan diantaranya mudah dibawa, karena berukuran kecil dan tipis, dilengkapi penjelasan yang ringkas dan sistematis sehingga mudah dipahami, namun tetap variatif dibandingkan dengan buku pelajaran, bahasa yang digunakan juga lebih mudah dipahami dan komunikatif, serta dilengkapi dengan gambar-gambar sebagai ilustrasi sehingga mempermudah dalam memahami penjelasan (Nuzalifa et al., 2019; Ulya, 2014; Yulianti et al., 2019). Booklet diharapkan dapat menjadi media pembelajaran yang dapat meningkatkan efektivitas pembelajaran peserta didik, salah satu kegunaan booklet yaitu sebagai suplemen bahan ajar.

Suplemen bahan ajar adalah bahan ajar yang menjadi pendamping bahan ajar pokok yang telah diterbitkan oleh pemerintah, suplemen bahan ajar biasanya berisi pengembangan materi sehingga pemahaman terhadap materi tersebut lebih luas (Owon \& Adi, 2017; Putri et al., 2018; Ramadhani et al., 2016). Sumplemen bahan ajar dapat dimanfaatkan oleh guru untuk membantu pelaksanaan pembelajaran, agar dapat membuat pelaksanaan pembelajaran lebih efektif dan siswa lebih memahami materi yang disampaikan oleh guru (Muharram et al., 2010; Putri et al., 2018; Wahyuning et al., 2017). Sehingga, penting dilaksanakan pengembangan mengenai analisis kebutuhan pengembangan booklet sistem imun manusia sebagai suplemen bahan ajar biologi. Penelitian ini didukung beberapa penelitian terdahulu yang relevan dengan penelitian ini, seperti: (1) penelitian yang dilakukan oleh (Rehusisma et al., 2017), yang mendapatkan hasil penelitian yaitu pengembangan media pembelajaran booklet dan video dapat menguatkan karakter hidup bersih dan sehat siswa; (2) penelitian yang dilakukan oleh (Nuzalifa et al., 2019), yang mendapatkan hasil penelitian yaitu pengembangan media pembelajaran booklet dapat digunakan untuk membantu penyuluhan tentang pembuatan nata de melon bagi masyarakat petani; (3) penelitian yang dilakukan oleh (Yusuf et al., 2019), yang mendapatkan hasil penelitian yaitu pengembangan bahan ajar perang lasem dalam bentuk booklet efektif digunakan untuk membantu pelaksanaan pembelajaran sejarah. Implikasi pelaksanaan penelitian pengembangan ini adalah dapat meningkatkan efektivitas peserta didik didalam proses pembelajaran, dan media booklet memiliki keunggulan mudah dibawa, karena berukuran kecil dan tipis, dilengkapi penjelasan yang ringkas dan sistematis sehingga mudah dipahami, serta dilengkapi dengan gambar-gambar sebagai ilustrasi.

\section{Simpulan dan Saran}

Berdasarkan data hasil penelitian dan pembahasan yang telah dilakukan dapat disimpulkan bahwa pengembangan booklet sebagai suplemen bahan ajar biologi dapat menjadi solusi dari permasalahan yang dihadapi oleh guru dan peserta didik khusunya pada materi sistem imun manusia. Implikasi pelaksanaan penelitian pengembangan ini adalah dapat meningkatkan efektivitas peserta didik didalam proses pembelajaran, dan media booklet memiliki keunggulan mudah dibawa, karena berukuran kecil dan tipis, dilengkapi penjelasan yang ringkas dan sistematis sehingga mudah dipahami, serta dilengkapi dengan gambar-gambar sebagai ilustrasi.

\section{Daftar Rujukan}

Aprinawati, I. (2017). Penggunaan Media Gambar Seri Untuk Meningkatkan Kemampuan Berbicara Anak Usia Dini. Jurnal Obsesi: Jurnal Pendidikan Anak Usia Dini, 1(1), 72. https: //doi.org/10.31004/obsesi.v1i1.33.

Bayu, G. W., \& Wahyuni, L. G. E. (2019). Efektifitas Implementasi Strategi Enjoyable Learning Berbantuan Media Audio Visual Terhadap Hasil Belajar Bahasa Inggris Permulaan Peserta Didik Sekolah Dasar. Jurnal Ilmiah Sekolah Dasar, 3(3), 335-341. 
Firdaus, H., Sugiyono, \& Purnama, S. K. (2018). The Development Model of Badminton Base Technique Training Based of Audio Visual Media for The Beginner Athlete. Jurnal Pendidikan: Teori, Penelitian, Dan Pengembangan, 3(2), 210-214. https://doi.org/10.17977/jptpp.v3i2.10734.

Handayani, N. M. D., Ganing, N. N., \& Suniasih, N. W. (2017). Model Pembelajaran Picture and Picture Berbantuan Media Audio-Visual Terhadap Kompetensi Pengetahuan IPA. Journal of Education Technology, 1(3), 176-182. https://doi.org/10.23887/jet.v1i3.12502.

Kawi. (2019). Pengaruh Model Pembelajaran Auditory, Intellectualy, Repetition Berbantuan Media Audio Visual terhadap Kompetensi Pengetahuan IPA. Internatonal Journal of Elementary Education, 3(1), 70-78. https://doi.org/10.23887/ijee.v3i1.17658.

Khaulani, F., Noviana, E., \& Witri, G. (2019). Penerapan Metode Brainstorming Dengan Bantuan Media Gambar Grafis Untuk Meningkatkan Hasil Belajar PKN Siswa Kelas V SD Negeri 009 Pulau Kecamatan Bangkinang Kabupaten Kampar. Jurnal PAJAR (Pendidikan Dan Pengajaran), 3(1), 1825. https://doi.org/10.33578/pjr.v3i1.6305.

Maharwati, N. K. (2019). Upaya Meningkatkan Kemampuan Berbahasa Lisan Anak Paud Berbantuan Media Gambar Melalui Metode Bercerita. Journal of Education Technology, 2(1), 6. https://doi.org/10.23887/jet.v2i1.13800.

Muharram, Lodang, H., Nurhayati, \& Tanrere, M. (2010). Pengembangan Model Pembelajaran IPA SD Berbasis Bahan Di Lingkungan Sekitar Melalui Pendekatan Starter Eksperimen. Jurnal Pendidikan Dan Kebudayaan, 16(3), 311-320. https://doi.org/10.24832/jpnk.v16i9.522.

Nuzalifa, Y. U., Hastuti, U. S., \& Sueb, S. (2019). Pengembangan Media Pembelajaran Booklet Penyuluhan tentang Pembuatan Nata de Melon bagi Masyarakat Petani. Jurnal Pendidikan: Teori, Penelitian, Dan Pengembangan, 4(3). https://doi.org/10.17977/jptpp.v4i3.12082.

Owon, S., \& Adi, R. (2017). Pengembangan Bahan Ajar Menulis Berbagai Jenis Teks Bertema Kearifan Lokal Sikka Bagi Siswa SMP. JINoP (Jurnal Inovasi Pembelajaran), 3(1), 528-541. https://doi.org/10.22219/jinop.v3i1.4318.

Paramita, R., Panjaitan, R. G. P., \& Ariyati, E. (2019). Pengembangan Booklet Hasil Inventarisasi Tumbuhan Obat Sebagai Media Pembelajaran Pada Materi Manfaat Keanekaragaman Hayati. JIPI (Jurnal IPA Dan Pembelajaran IPA), 2(2), 83-88. https://doi.org/10.24815/jipi.v2i2.12389.

Pradilasari, L., Gani, A., \& Khaldun, I. (2019). Pengembangan Media Pembelajaran Berbasis Audio Visual pada Materi Koloid Untuk Meningkatkan Motivasi dan Hasil Belajar Siswa SMA. Jurnal Pendidikan Sains Indonesia. https://doi.org/10.24815/jpsi.v7i1.13293.

Putri, I. H. N., Sholihah, U., Handayani, E. M., \& Sumarmi, S. (2018). Pengembangan Suplemen Bahan Ajar Digital Pada Mata Pelajaran Geografi Dengan Topik Bahasan Sumber Daya Laut Berbasis Kearifan $\begin{array}{lllll}\text { Lokal. Jurnal Pendidikan } & \text { Geografi, }\end{array}$ https://doi.org/10.17977/um017v23i22018p078.

Ramadhani, R., Hs, W., \& Harsiati, T. (2016). Pengembangan Bahan Ajar Keterampilan Berbicara Bahasa Indonesia Bagi Penutur Asing Tingkat Pemula. Jurnal Pendidikan - Teori, Penelitian, Dan Pengembangan, 1(3), 326-337. https://doi.org/10.17977/jp.v1i3.6155.

Rehusisma, L. A., Indriwati, S. E., \& Suarsini, E. (2017). Pengembangan Media Pembelajaran Booklet Dan Video Sebagai Penguatan Karakter Hidup Bersih Dan Sehat. Jurnal Pendidikan: Teori, Penelitian, Dan Pengembangan, 2(9). https://doi.org/10.17977/jptpp.v2i9.9964.

Rivaldi, K. H. O., Putra, D. K. N. S., \& Putra, I. K. A. (2018). Pengaruh Model Pembelajaran Problem Based Learning Berbantuan Audio Visual Terhadap Penguasaan Kompetensi Pengetahuan IPA. Jurnal Ilmiah Sekolah Dasar, 2(2), 128. https://doi.org/10.23887/jisd.v2i2.15494.

Septiani, M. T., \& Hasanah, M. (2019). Media Audio Visual untuk Pembelajaran Musikalisasi Puisi. BASINDO: Jurnal Kajian Bahasa, Sastra Indonesia, Dan Pembelajarannya, 3(1), 31-37. https: //doi.org/10.17977/um007v3i12019p031.

Septiawan, E. I. M. A. (2018). Pengaruh Model Pembelajaran Time Token Berbantuan Media Audio Visual Terhadap Hasil Belajar IPS. Jurnal Penelitian Dan Pengembangan Pendidikan, 2(3), 271. https://doi.org/10.23887/jppp.v2i3.16285.

Sribawana, I. P. S. S., Kusmariyatni, N., \& Suwatra, I. I. W. (2017). Pengaruh Model Pembelajaran Problem Based Learning Berbantuan Media Gambar Terhadap Hasil Belajar IPA Kelas IV. Mimbar PGSD Undiksha, 5(2), 1-12. https://doi.org/10.23887/jjpgsd.v5i2.10934.

Sulfemi, W. B., \& Mayasari, N. (2019). Peranan Model Pembelajaran Value Clarification Technique Berbantuan Media Audio Visual Untuk Meningkatkan Hasil Belajar IPS. Jurnal Pendidikan, 20(1), 53-68. https://doi.org/10.33830/jp.v20i1.235.2019.

Ulfah, D. M., \& Soenarto, S. (2017). Pengaruh penggunaan media video dan gambar terhadap keterampilan menulis kelas V. Jurnal Prima Edukasia, 5(1), 22-34. https://doi.org/10.21831/jpe.v5i1.7693.

Ulya, E. (2014). Efektivitas Media Booklet Braille Dalam Meningkatkan Pengetahuan Gizi Pada Anak 
Tunanetra. UNNES Journal Of Public Health, 3(4). https://doi.org/10.15294/ujph.v3i4.3888.

Wahyuning, D. A., Gipayana, M., \& Djatmika, E. T. (2017). Pengembangan Bahan Ajar Berbasis Literasi Bercirikan Quantum Teaching Untuk Mengoptimalkan Pembelajaran Efektif Dan Produktif. Jurnal Pendidikan: Teori, Penelitian, Dan Pengembangan, 2(5), 667-675. https://doi.org/10.17977/jptpp.v2i5.10144.

Wicaksana, N. (2017). Pengaruh Model Pembelajaran Open Ended Berbantuan Media Audio Visual Dan Motivasi Terhadap Kompetensi Pengetahuan Matematika. Mimbar PGSD Undiksha, 5(2). https://doi.org/10.23887/jjpgsd.v5i2.11074.

Wicaksono, A. G., Jumanto, \& Oka, I. (2020). Pengembangan media komik komsa materi rangka pada pembelajaran IPA di sekolah dasar. Premiere Educandum: Jurnal Pendidikan Dasar Dan Pembelajaran, 10(2), 215-226. https://doi.org/10.25273/pe.v10i2.6384.

Wintarti, W. (2017). Upaya Meningkatkan Prestasi Belajar IPS Melalui Model Pembelajaran DI (Direct Instruction) Dengan Media Visual Berbantuan Komputer. Premiere Educandum, 7(1), 28-38. https://doi.org/10.25273/pe.v7i01.1161.

Yulianti, Maharani, N. A. F. D., \& Kumala, F. N. (2019). Pengembangan Media E-Booklet Materi Zat Untuk Meningkatkan Karakter Siswa SD Islamic Global School Malang. Elementary School, 6(2), 112-119. https://doi.org/10.31316/esjurnal.v6i2.269.

Yusantika, F. D., Suyitno, I., \& Furaidah. (2018). Pengaruh Media Audio dan Audio Visual terhadap Kemampuan Menyimak Siswa Kelas IV. Jurnal Pendidikan, 3(2), 251-258. http://dx.doi.org/10.17977/jptpp.v3i2.10544.

Yusuf, M., Saraswati, U., \& Ahmad, T. A. (2019). Pengembangan Bahan Ajar Perang Lasem dalam Bentuk Booklet Untuk Pembelajaran Sejarah Lokal di SMA Negeri 1 Lasem. Indonesian Journal Of History Education, 7(1), 50-58. https://doi.org/10.15294/ijhe.v7i1.32287. 